Article

\title{
Aircraft Turbine Engine Labyrinth Seal CFD Sensitivity Analysis
}

\author{
Michal Č́ižek *(D), Zdeněk Pátek and Tomáš Vampola \\ Center of Aviation and Space Research, Czech Technical University in Prague, Faculty of Mechanical \\ Engineering, Jugoslávských partyzánů 1580/3, 16636 Prague, Czech Republic; zdenek.patek@fs.cvut.cz (Z.P.); \\ Tomas.Vampola@fs.cvut.cz (T.V.) \\ * Correspondence: michal.cizek@fs.cvut.cz; Tel.: +42-0224-359-775
}

Received: 1 September 2020; Accepted: 24 September 2020; Published: 29 September 2020

\begin{abstract}
This article presents the labyrinth seal radial clearance influence. A generic labyrinth seal of a turbine aircraft engine was modeled. The target is to compare and analyze the influence of the radial clearance and location of teeth. The results can be useful for designing the location of teeth and their appropriate setting, especially for materials engineering and engineering technology in general.
\end{abstract}

Keywords: labyrinth seal; aircraft turbine engine; radial clearance

\section{Introduction}

The aircraft turbine engine consists of three fundamental segments - a compressor, a combustion segment, and a turbine [1]. The connection between the compressor disc and the turbine disc is provided by a rotating shaft. Part of the engine performance loss originates between the rotating shaft and the stator case, because the secondary air flows here and does not follow the primary path [2]. A labyrinth seal is a way of suppressing the airflow in cavities between the shaft and the case $[3,4]$. Current turbomachinery (not only aircraft engines) is facing problems of reducing the airflows outside the primary air flow path, but simultaneously there are problems with the necessity of turbine blade cooling $[4,5]$ and bearings control [6] requiring fresh airflow. The labyrinth seal is advantageous due to its relatively simple manufacture procedure and the fact that its use does not disrupt the balancing of the shaft. A relevant geometric parameter of the labyrinth seal is its radial clearance (RC), i.e., the radial length of the gap between the labyrinth seal teeth and the opposite wall. Due to the contactless disposition, the radial clearance cannot be zero and it is evident that it will increase during operation life of the engine. The aim of this article is, based on the computational fluid dynamics (CFD) [4], to clarify and describe the influence of the radial clearance on the thermodynamic parameters of the labyrinth seal.

The physical principle of the turbomachinery labyrinth seal operation is energy loss in cavities between the teeth in the seal; the loss practically restrains the parasitic flow between the rotating shaft and the fixed case. Because the labyrinth seal is contactless, the air flows and thus a vortex is developed between the teeth. Modern labyrinth seals are characterized by pressure and mass flow drop, named sealing effect. Initial results of research can be found in the steam turbine's design. However, the important difference between a steam turbine and a turbine engine consists of very different angular velocities of the shaft. In steam turbines, the velocity is approximately $500 \mathrm{rad} / \mathrm{s}$ and, in turbine engines, it is approximately $4100 \mathrm{rad} / \mathrm{s}[1,7,8]$. Literature sources addressing the topic are rather rare [9-11]. In the presented article, the influence of different settings of the radial clearance and different locations of the teeth are examined, developing the previous research presented in [12]. The number of teeth was out of interest. The typical number of teeth $[3,5,13]$ used was equal to four, because it corresponds to the standard conditions in labyrinth seals. 


\section{Labyrinth Seal Geometry}

The labyrinth seal geometry consists of 5 geometric values. All geometric values were represented by parameters that are typical for the turbine engine labyrinth seals [3]:

- Shaft radius $201388 \mathrm{~mm}$

- Thickness of the teeth- $0.57 \mathrm{~mm}$

- Height of the flow channel-2.54 mm

- Length of the seal cavity-2.15 mm

All teeth have a rectangular cross-section. Two variants of the locations of the teeth are studied-with the first inlet location being on the rotor (i.e., teeth are rotating) and the second one being on the stator (i.e., teeth are non-rotating). The CFD geometry consists of 3 segments. The first inlet segment is a non-rotating conical segment where the inlet boundary conditions are defined; second segment is a rotating labyrinth seal conical segment where the labyrinth seal geometry is modeled; and third segment is a non-rotating conical segment where the outlet boundary conditions are defined. The inlet and the outlet segments are inserted to stabilize and monitor the air flow in the channel. All segments consist of $5^{\circ}$ conical elements.

In Figures 1 and 2, the considered setup is presented. In both (rotor and stator teeth) variants, the labyrinth teeth have a rectangular cross-section. The air is flowing from the left to the right. Four different $R C$ are applied for both variants. Dimensionless corrected radial clearance $R C_{C O R R}$ is used as a geometric parameter

$$
R C_{\mathrm{CORR}}=\frac{R C}{R C_{F}}
$$

where $R C_{F}$ is the radial clearance between the shaft and the case without considering the presence of the teeth (e.g., $0.2 \mathrm{~mm}$ ). All variants of $R C_{C O R R}$ are listed in Table 1 . The significance of the font colors is described in Chapter 0.

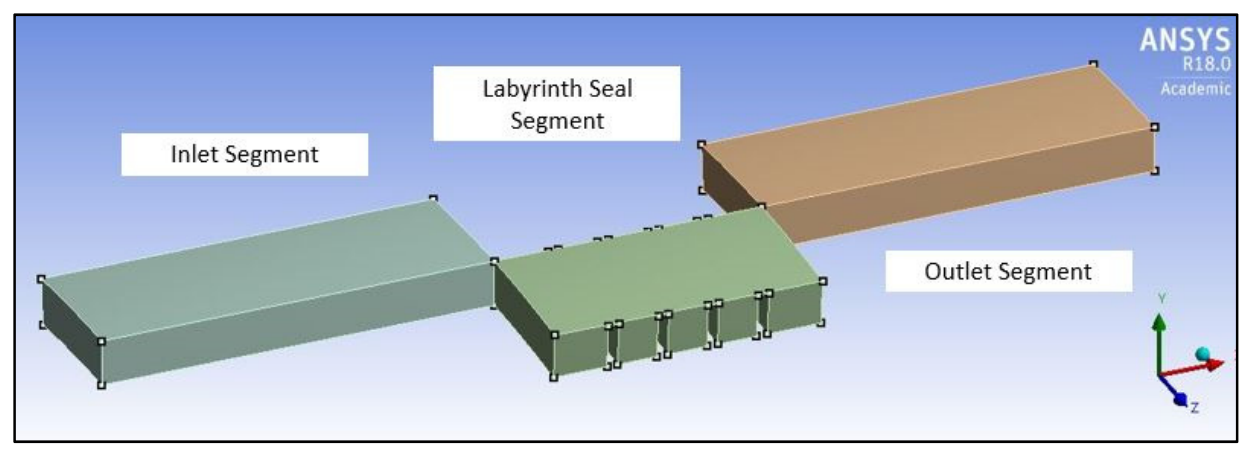

Figure 1. Considered setup with rotor labyrinth teeth.

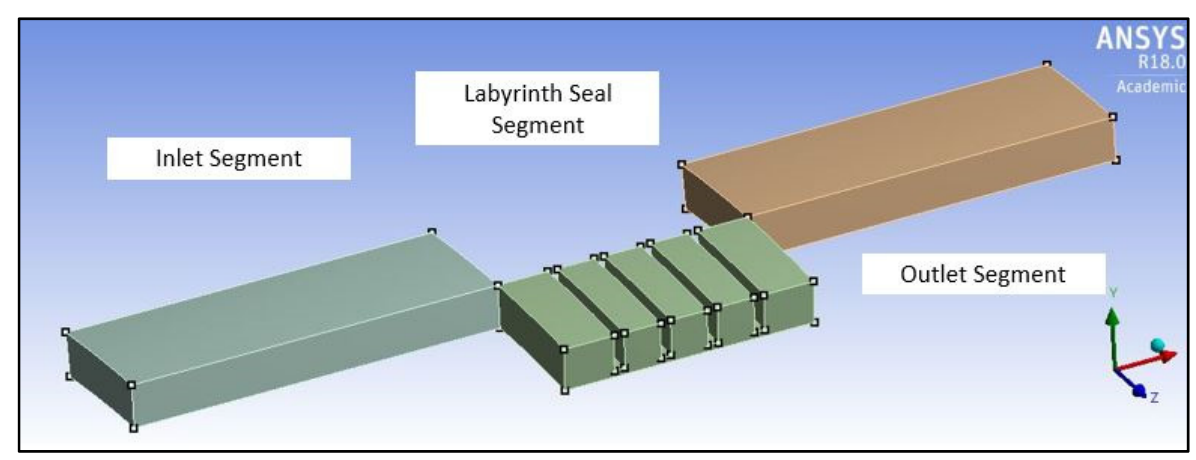

Figure 2. Considered setup with stator labyrinth teeth. 
Table 1. Radial clearances.

\begin{tabular}{cc}
\hline Teeth Position & RC $_{\text {CORR }}[-]$ \\
\hline Rotor & 0.04 \\
Rotor & 0.15 \\
Stator & 0.04 \\
Stator & 0.15 \\
\hline
\end{tabular}

\section{Simulation Mesh and Calculation}

\subsection{Simulation Mesh}

All simulation meshes were prepared in the ANSYS Meshing software, the mapping mesh was applied. Based on the experience in [13], the tetrahedral- and hexahedral-mapped mesh with influences in all walls was selected as a suitable variant. The mesh in the labyrinth seal segment has 2.4 million of elements in the inlet and in the outlet, segments have 0.5 million of elements. Twenty-five rows of elements were applied in the critical flow path in the location of the radial clearance. The calculation mesh example is in Figure 3.

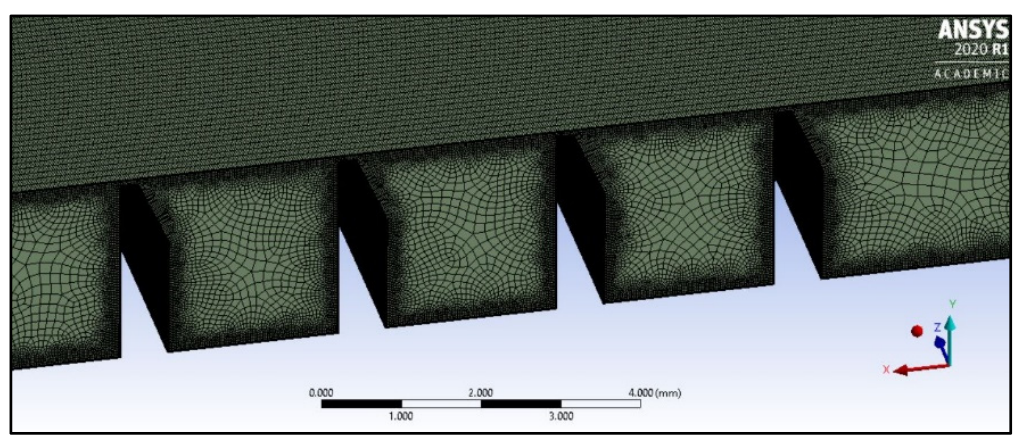

Figure 3. Calculation mesh.

\subsection{Boundary Conditions}

The boundary conditions were set to the constant pressure ratio $\pi_{R}$ that is defined by (2):

$$
\pi_{R}=\frac{p_{T I N}}{p_{\text {SOUT }}}
$$

where $p_{\text {TIN }}[\mathrm{Pa}]$ is the inlet total pressure and $p_{\text {SOUT }}[\mathrm{Pa}]$ is the outlet static pressure.

The angular velocity ratio $\omega_{C}$ is defined by (3):

$$
\omega_{C}=\frac{\omega_{A}}{\omega_{F}}
$$

where $\omega_{A}[\mathrm{rad} / \mathrm{s}]$ is the current angular velocity and $\omega_{F}[\mathrm{rad} / \mathrm{s}]$ is the reference angular velocity, as it is in [1] (e.g., 30e03 RPM). The list of the boundary conditions is in Table 2:

Table 2. Boundary conditions.

\begin{tabular}{cc}
\hline$\pi_{R}[-]$ & $\omega_{C}[-]$ \\
\hline 2.467 & 0.02 \\
2.467 & 0.05 \\
2.467 & 0.08 \\
2.467 & 0.11 \\
2.467 & 0.14 \\
2.467 & 0.16 \\
\hline
\end{tabular}


Table 2. Cont.

\begin{tabular}{cc}
\hline$\pi_{R}[-]$ & $\omega_{C}[-]$ \\
\hline 2.467 & 0.19 \\
2.467 & 0.22 \\
2.467 & 0.25 \\
2.467 & 0.27 \\
2.467 & 0.41 \\
2.467 & 0.55 \\
2.467 & 0.68 \\
2.467 & 1 \\
\hline
\end{tabular}

The calculations were performed in the ANSYS CFX Software. The fluid was set as the air ideal gas with the ratio of specific heats $\mathrm{k}=1.4$. Based on $[8,11,14,15]$, the standard two-equation $\mathrm{k}-\varepsilon$ turbulent model [4] was set. The time step was set the same as in [12]. In the rotor labyrinth teeth scheme (Figure 1), the labyrinth seal segment was rotated and, in the opposite side "counter rotation wall" condition, (i.e., the same rotating speed at the opposite side) was defined in the stator wall. In the stator labyrinth teeth setup (Figure 2), only the shaft wall without the teeth was rotated. Between segments is defined the interface wall. The total pressure inlet and static pressure outlet were defined, corresponding to $\pi_{R}$ listed in Table 2. On the sides, the periodical conditions were defined. The rotor boundary conditions are presented in Figure 4 and the stator boundary conditions are presented in Figure 5.

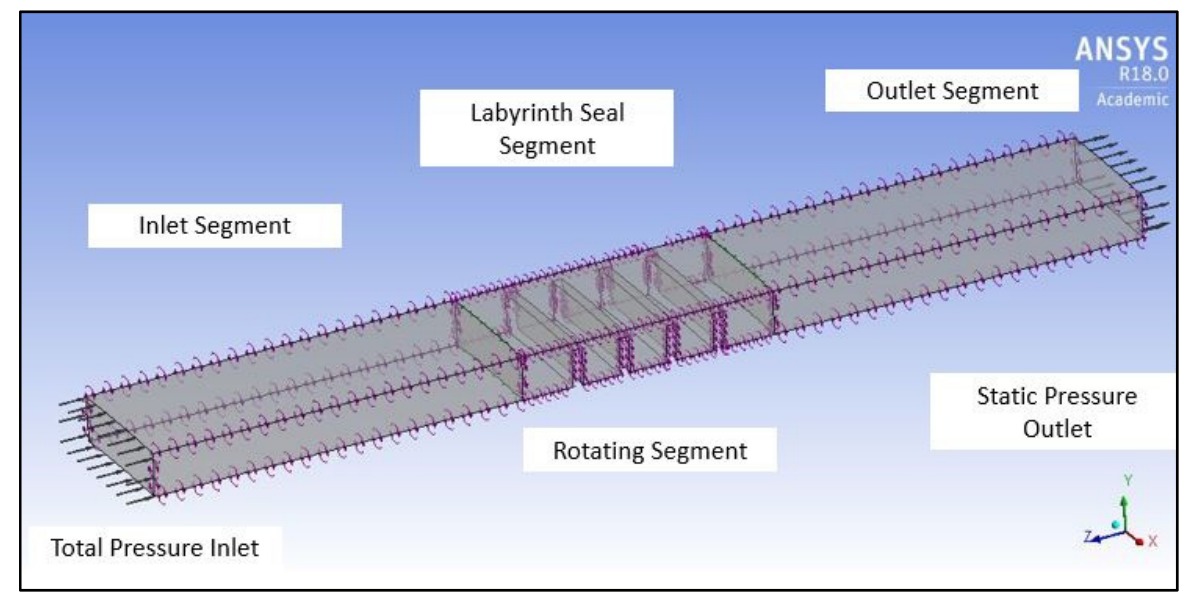

Figure 4. Rotor teeth boundary conditions.

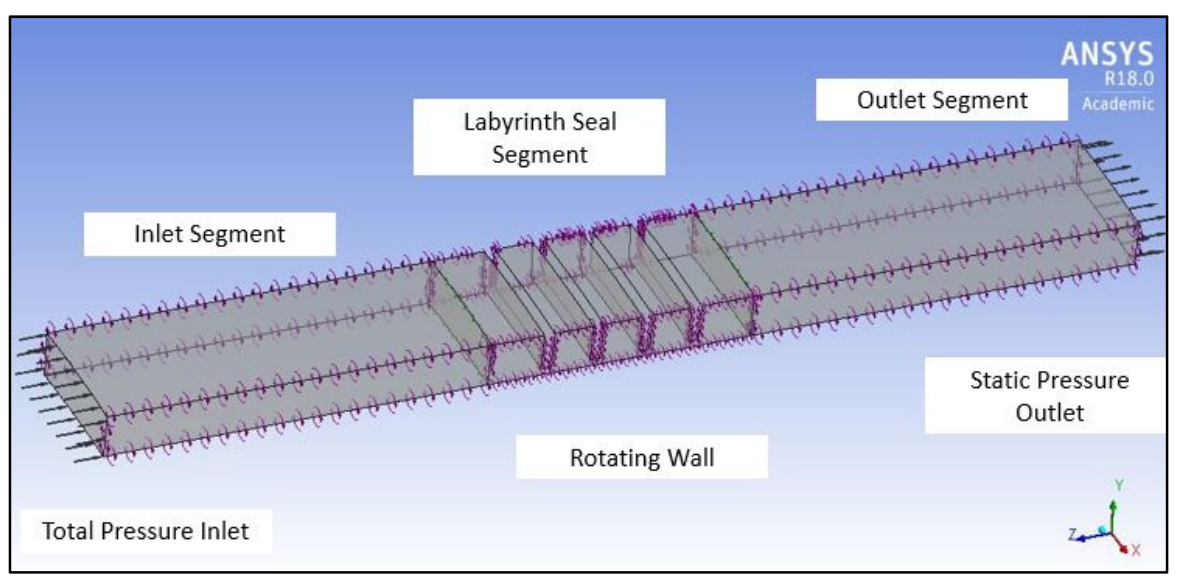

Figure 5. Stator teeth boundary conditions. 


\subsection{Calculation and Convergence}

All calculations were finished after 1000 iterations, where the residuals were converged to the value lower than 1E-03. The residuals, turbulent, and mass flow were monitored. The turbulent parameters show a trend similar to the residuals (Figure 6), i.e., less than 1E-03 (Figure 7). The mass flow value convergence trend (Figure 8) shows that at the inlet (pink curve) and at the outlet (green curve), the residuals are similar (the negative values here as the gas flows are out of the domain). It is possible to say that the calculation was converged well.

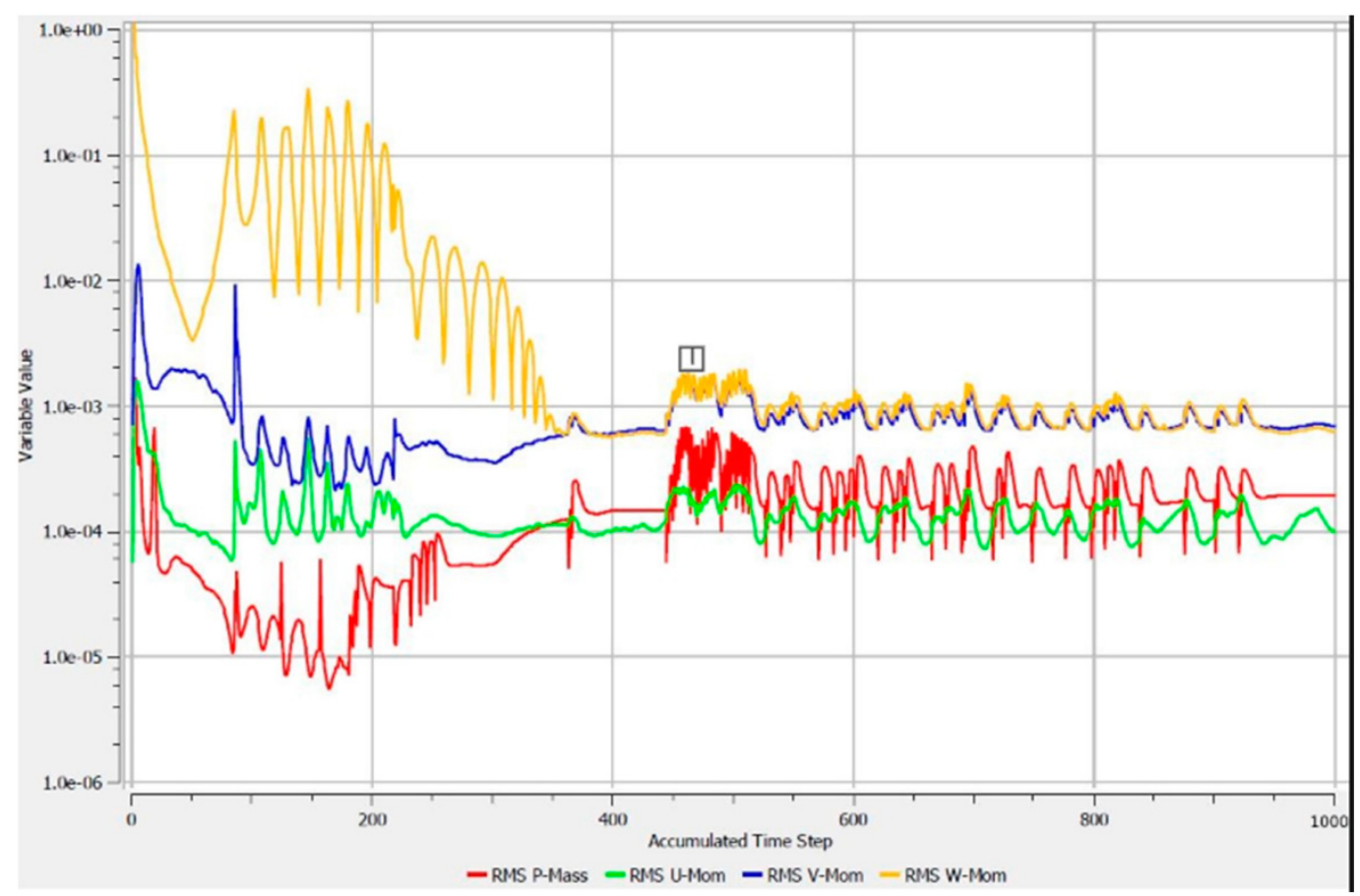

Figure 6. Residuals convergence.

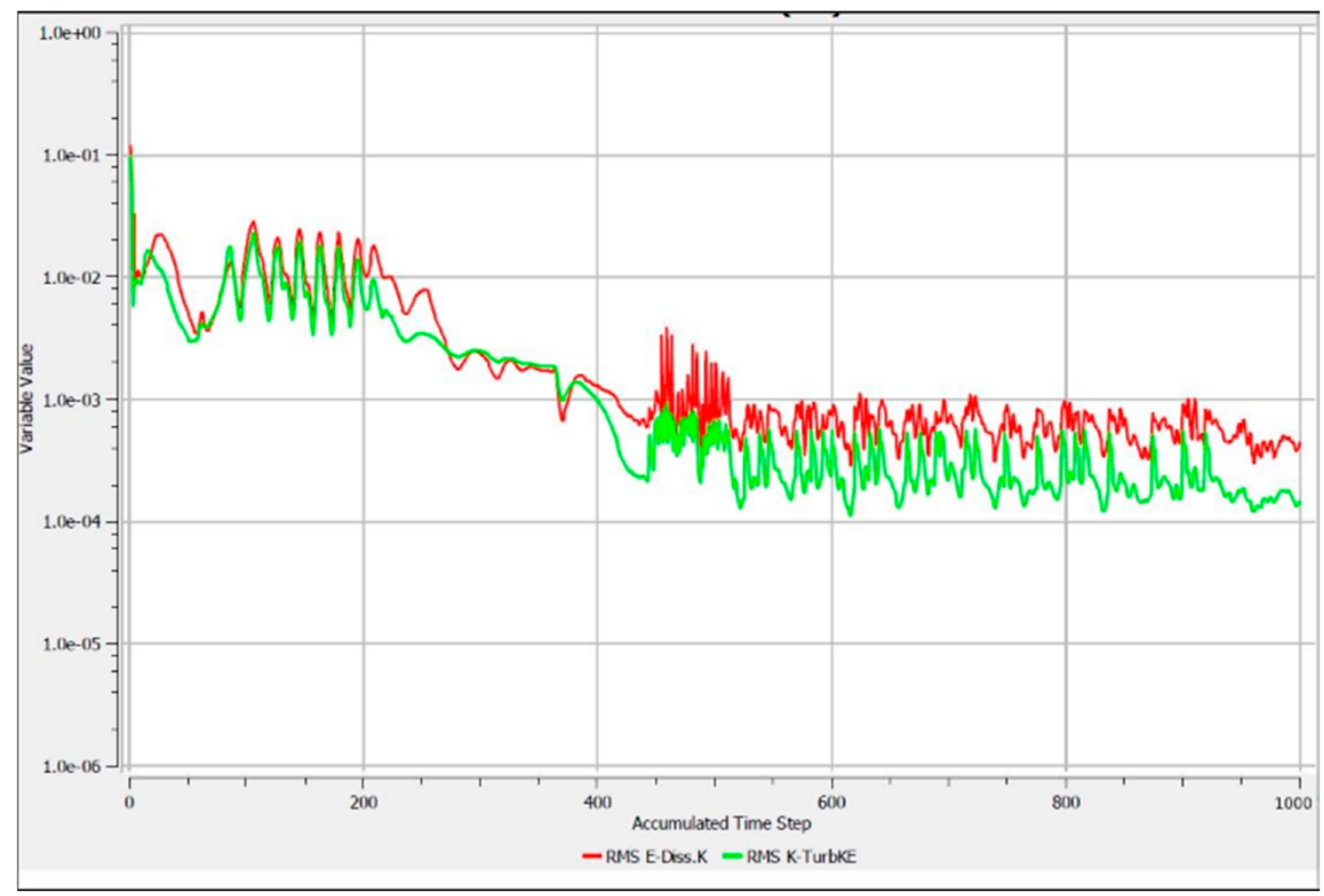

Figure 7. Turbulent convergence. 


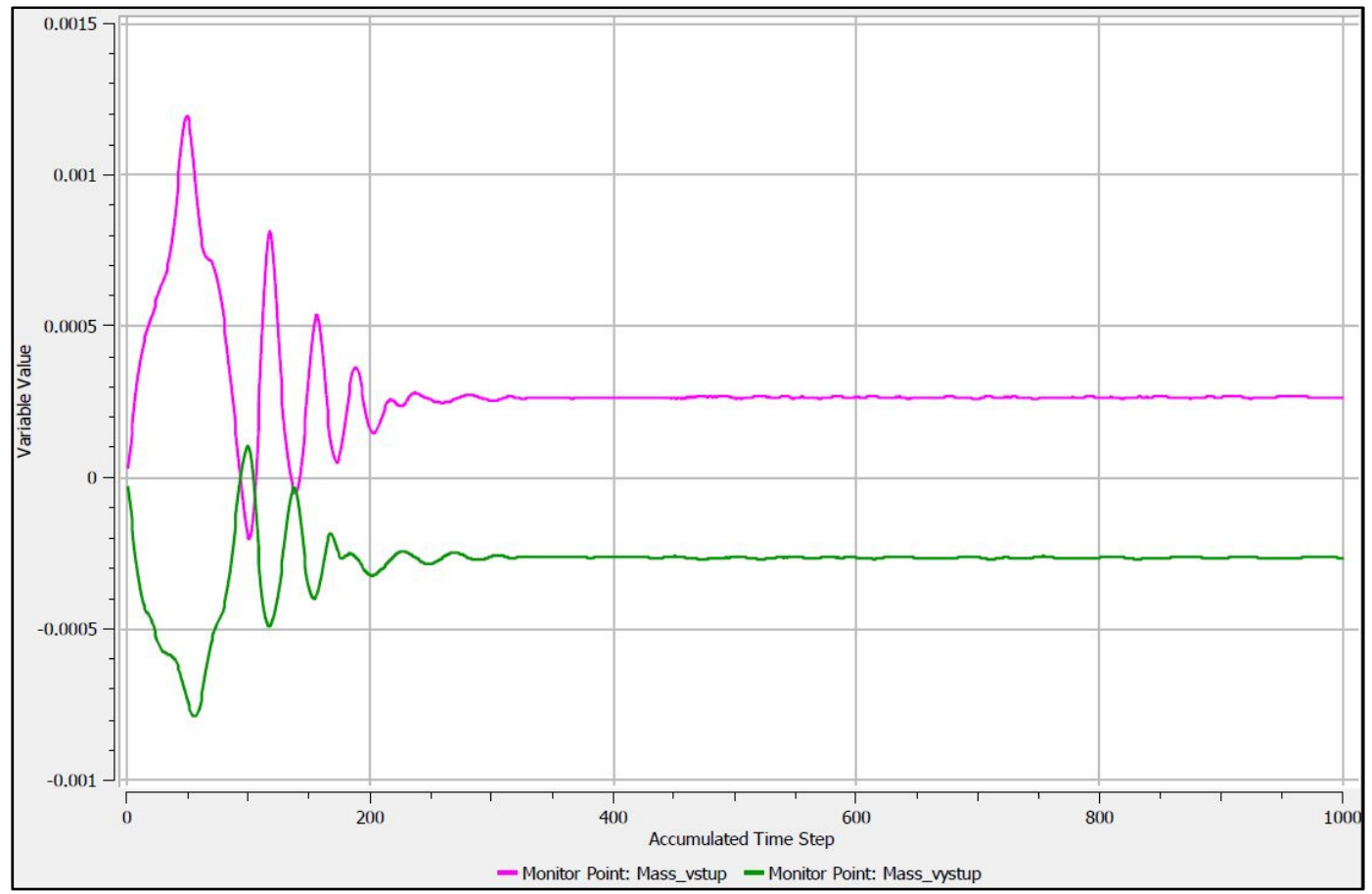

Figure 8. Mass flow convergence.

\section{Calculation Discussion}

The aim is to obtain deeper understanding of the thermodynamics in a turbine engine labyrinth seal at different angular velocities $\omega_{C}$, different radial clearances $R C_{C O R R}$, and different locations of the teeth. The total temperature, static pressure, total enthalpy, flow coefficient, kinetic energy, and density were chosen as evaluation parameters.

Based on the following Formulas (4)-(10), all average values of thermodynamic parameters were plotted.

- Total temperature

$$
T_{\text {TCORR }}=\frac{T_{T}}{T_{T F}}
$$

where $T_{T}[\mathrm{~K}]$ is the calculated total temperature and $T_{T F}[\mathrm{~K}]$ is the reference total temperature.

- $\quad$ Static pressure

$$
p_{S C O R R}=\frac{p_{S}}{p_{S F}}
$$

where $p_{S}[\mathrm{~Pa}]$ is the calculated static pressure and $p_{S F}[\mathrm{~Pa}]$ is the reference static pressure.

- Total enthalpy

$$
h_{T C O R R}=\frac{h_{T}}{h_{T F}}
$$

where $h_{T}[\mathrm{~kJ} / \mathrm{kg}]$ is the total enthalpy and $h_{T F}[\mathrm{~kJ} / \mathrm{kg}]$ is the reference total enthalpy

- $\quad$ Flow coefficient

$$
\mu=\frac{Q}{Q_{C}}
$$

where $Q[\mathrm{~kg} / \mathrm{s}]$ is the calculated mass flow and $Q_{C}[\mathrm{~kg} / \mathrm{s}]$ is the critical mass flow, defined by (8)

$$
Q_{C}=\pi \cdot R C^{2} \cdot \sqrt{\frac{2 \cdot k}{k+1} \cdot r \cdot T_{0}} \cdot\left[\rho_{0} \cdot\left(\frac{2}{k+1}\right)^{\frac{1}{k-1}}\right]
$$


where $k$ is the Poisson constant $[-], r$ is the Gas constant $[\mathrm{J} / \mathrm{kg} / \mathrm{K}], T_{0}[\mathrm{~K}]$ is the ambient total temperature, and $\rho_{0}$ is the ambient density $\left[\mathrm{kg} / \mathrm{m}^{3}\right]$. Ambient conditions are values near the teeth.

- $\quad$ Kinetic energy

$$
E k_{\mathrm{CORR}}=\frac{E k}{E k_{F}}
$$

where $E k_{F}$ is $[\mathrm{kJ}]$ is the reference kinetic energy.

- Density

$$
\rho_{\mathrm{CORR}}=\frac{\rho}{\rho_{F}}
$$

where $\rho_{F}\left[\mathrm{~kg} / \mathrm{m}^{3}\right]$ is the reference density.

A list of reference conditions (subscripted with $F$ ) is in Table 3:

Table 3. Reference conditions.

\begin{tabular}{ccc}
\hline Parameter & Value & Unit \\
\hline $\mathrm{T}_{\mathrm{TF}}$ & 288 & $\mathrm{~K}$ \\
$\mathrm{p}_{\mathrm{SF}}$ & 101325 & $\mathrm{~Pa}$ \\
$\mathrm{~h}_{\mathrm{TF}}$ & 260 & $\mathrm{~kJ} / \mathrm{kg}$ \\
$\mathrm{Ek}_{\mathrm{F}}$ & 200 & $\mathrm{~kJ}$ \\
$\rho_{\mathrm{F}}$ & 1.029 & $\mathrm{~kg} / \mathrm{m}^{3}$ \\
$\omega_{\mathrm{F}}$ & 3665 & $\mathrm{rad} / \mathrm{s}$ \\
\hline
\end{tabular}

The above stated thermodynamic parameters are plotted in the following charts. The angular velocity $\omega_{C}$ is plotted in the x-axis in all charts. The calculated data contains both the rotor teeth and stator teeth variants. The $\mathrm{RC}_{\mathrm{CORR}}$ values for the various teeth locations are listed in Table 1 . The total temperatures and the statics pressure fields for $\mathrm{RC}_{\mathrm{CORR}}=0.15$ are presented in Appendix $\mathrm{A}$. The same characteristics for $\mathrm{RC}_{\mathrm{CORR}}=0.04$ are presented in Appendix B. The font colors listed in Table 1 correspond to the colors used in the charts. The total temperature (based on (4)) trendlines are given in Figure 9. Here, the trendlines with the identical radial clearances have similar development. The differences (of approximately 0.03) can be seen at high angular velocities at minimal radial clearance. With a small radial clearance, the teeth positions (stator or rotor) do not show any influence; the trendlines are similar.

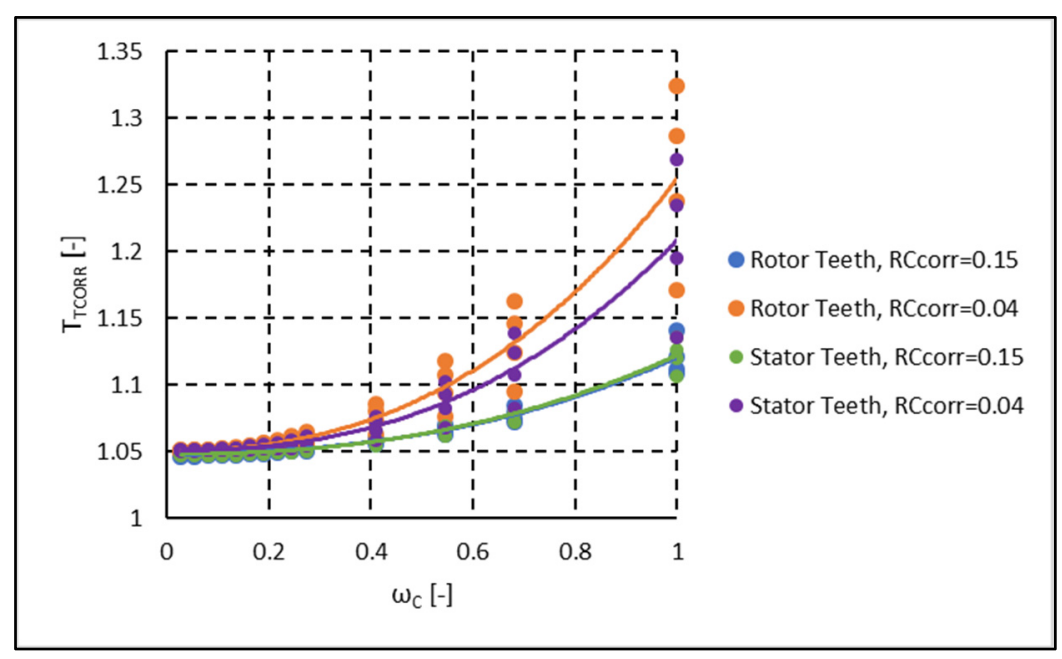

Figure 9. Total temperature trendlines. 
It is possible to say that the dominant factor of the total temperature increase is the radial clearance value. In Figure 10, the static pressure (based on (5)) trendlines are presented. It is visible that the static pressure is of nearly constant value. Similar results appear for different angular velocities, where only a small difference (approx. 0.05) at radial clearance 0.15 at maximal angular velocity is registered. With small radial clearance, the static pressure trendlines are moved to higher value (from 1.35 to 1.63 ). The main geometric parameter of the labyrinth seal to control the static pressure development is the radial clearance.

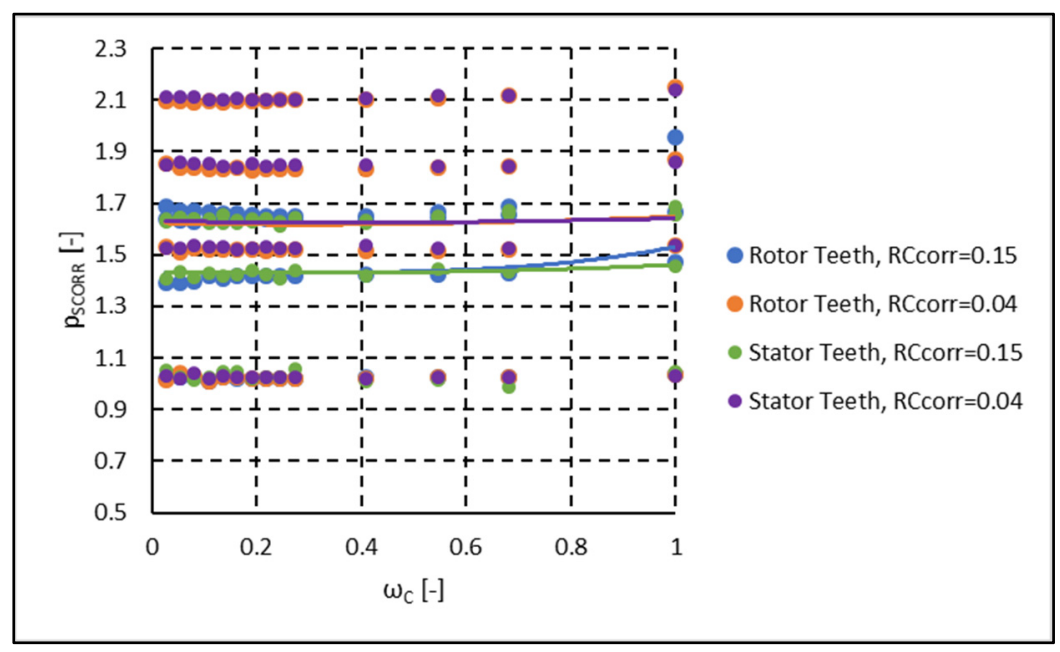

Figure 10. Static pressure trendlines.

The total enthalpy trendlines (based on (6)) are given in Figure 11. They correspond to the temperature trendline results. The main factor influencing the enthalpy is the radial clearance. The total enthalpy difference (approx. 0.05) at the highest angular velocity is similar to the total temperature difference. The flow coefficient trendlines (based on (7)) are given in Figure 12. The kinetic energy trendlines (based on (9)) are given in Figure 13. The density trendlines (based on (10)) are given in Figure 14. The main consequences of radial clearance in the rotor and stator teeth location are shown. If the radial clearance is 0.04 , the absolute value of the flow coefficient is higher than if the clearance is 0.15 . The sealing effect of the labyrinth seal is better with a low radial clearance (0.04) and teeth on the rotor.

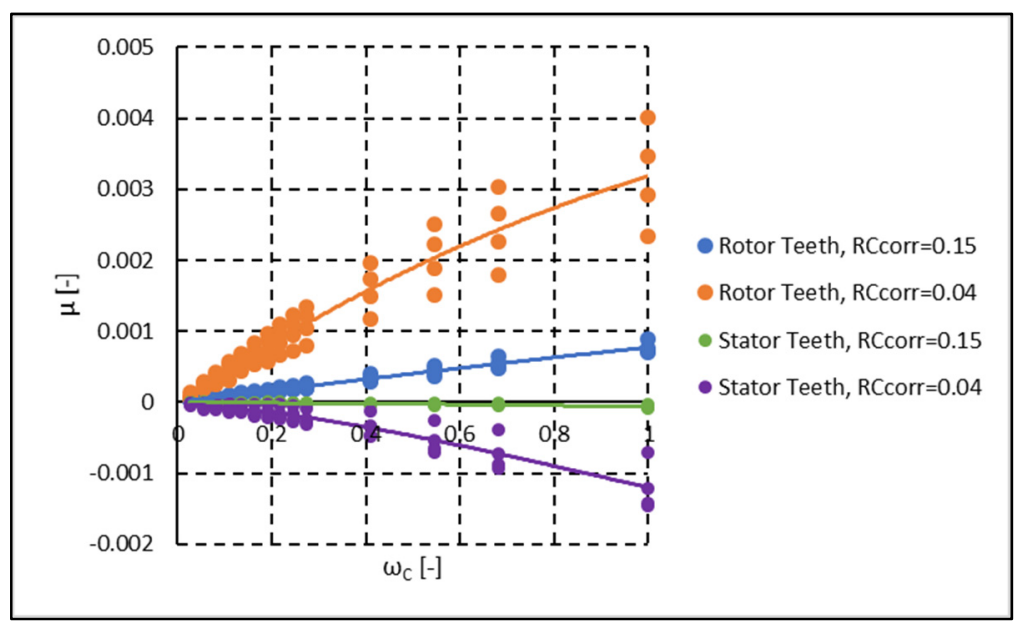

Figure 11. Total enthalpy trendlines. 


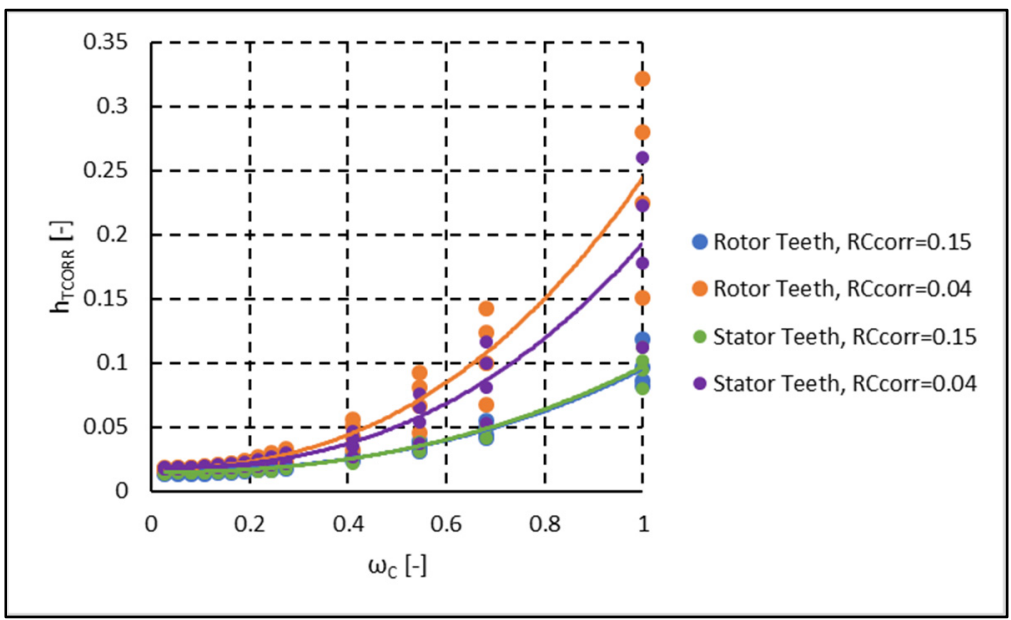

Figure 12. Flow coefficient trendlines.

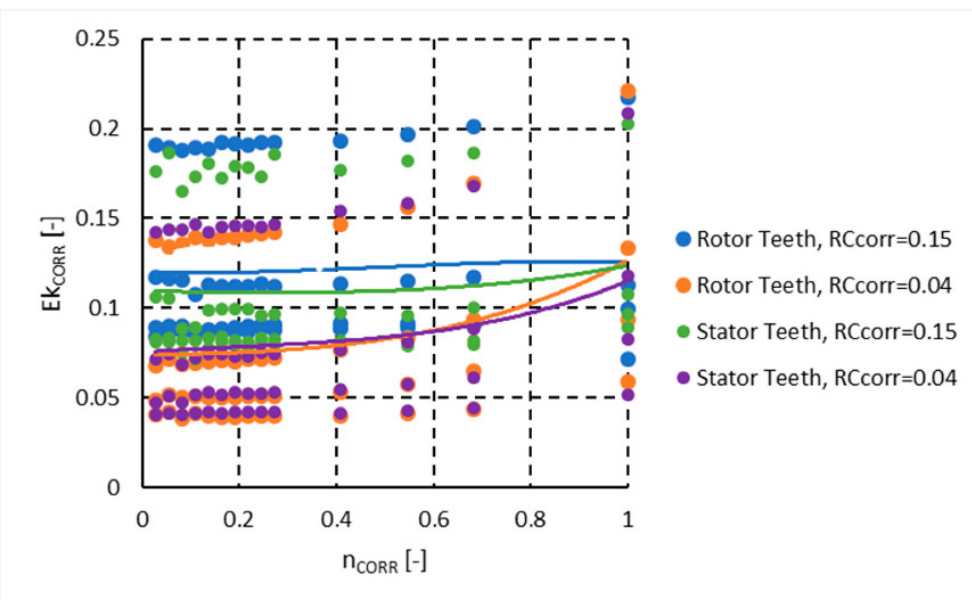

Figure 13. Kinetic energy trendlines.

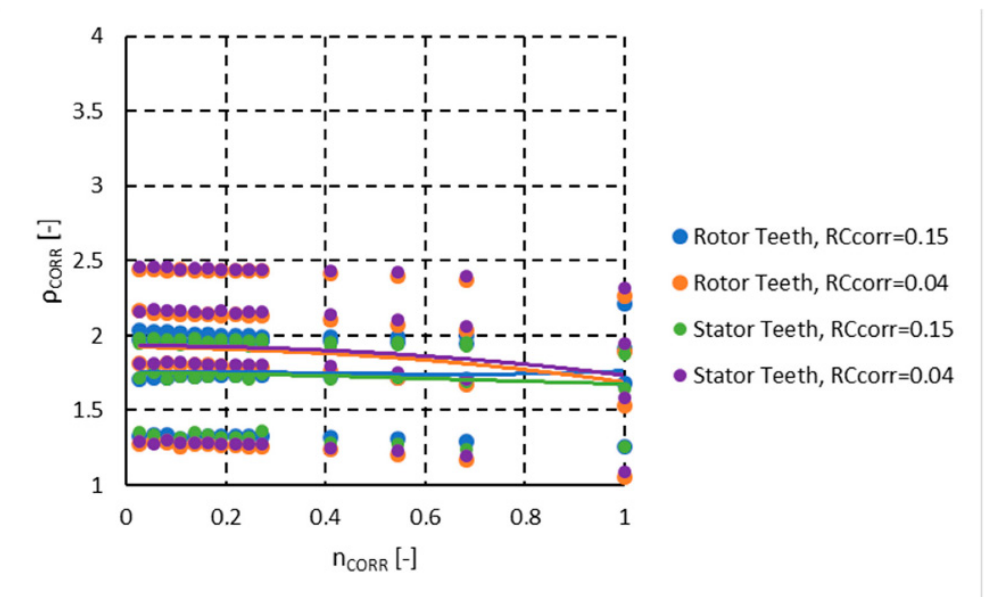

Figure 14. Density trendlines.

\section{Conclusions}

Typical thermodynamic parameters of a turbine engine labyrinth seal were simulated using the ANSYS CFX computational software. A constant number of four teeth was selected. The airflow in the labyrinth seal was modelled using the standard two-equations $\mathrm{k}-\varepsilon$ turbulence model. A study of the thermodynamic parameters was performed for four-geometry settings: two different teeth locations 
with two different radial clearances and for different angular velocities using the constant pressure ratio $\pi_{R}=2.467$. Based on the convergence charts (Figure 6, Figure 7, Figure 8), it was found that the numerical calculation method converged well and it is applicable to labyrinth seal computations. The results of the computations show that the total temperature (Figure 9) and total enthalpy (Figure 11) increase with increasing angular velocity. The next thermodynamic parameters, static pressure (Figure 10) and flow coefficient (Figure 12), correspond to expectations [3,11], i.e., static pressure decreases and total temperature increases. Similar results (i.e., kinetic energy increases and density decreases) were observed for the kinetic energy (Figure 12) and density (Figure 13). The labyrinth sealing effect (i.e., mass flow decrease) is not influenced by the angular velocity. The radial clearance has a dominant influence on the sealing effect; the location of teeth (i.e., the teeth either on the rotor or the stator) is of secondary importance. The phenomenon mentioned in all angular velocities can be seen, because in all plots the trendlines with the same radial clearance $\left(\mathrm{RC}_{\mathrm{CORR}}=0.04\right.$-orange and purple lines; $\mathrm{RC}_{\mathrm{CORR}}=0.15$-blue and green lines) have a similar trend.

The study presented other thermodynamic materials for better design of aircraft turbine engines. Based on the labyrinth seal improvements, better engine design could be possible, improving so the performance parameters (i.e., turbine temperature, compressor pressure ratio, thrust or power, etc.).

Author Contributions: Writing_original draft, M.C.; Writing—review \& editing, Z.P. and T.V. Software: M.C. and Z.P., Methodology M.C. and T.V. All authors have read and agreed to the published version of the manuscript.

Funding: This research received no external funding

Acknowledgments: Authors acknowledge the support of the ESIF, EU Operational Programme Research, Development and Education, and of the Center of Advanced Aerospace Technology (CZ.02.1.01/0.0/0.0/16_019/ 0000826), Faculty of Mechanical Engineering, Czech Technical University in Prague.

Conflicts of Interest: The authors declare no conflict of interest. 
Appendix A. $\mathrm{RC}_{\mathrm{CORR}}=0.15$, Total Temperature and Static Pressure Fields

Table A1. Total Temperature Fields.

$\omega_{C}=1 \mathrm{e}+00$

Stator Teeth

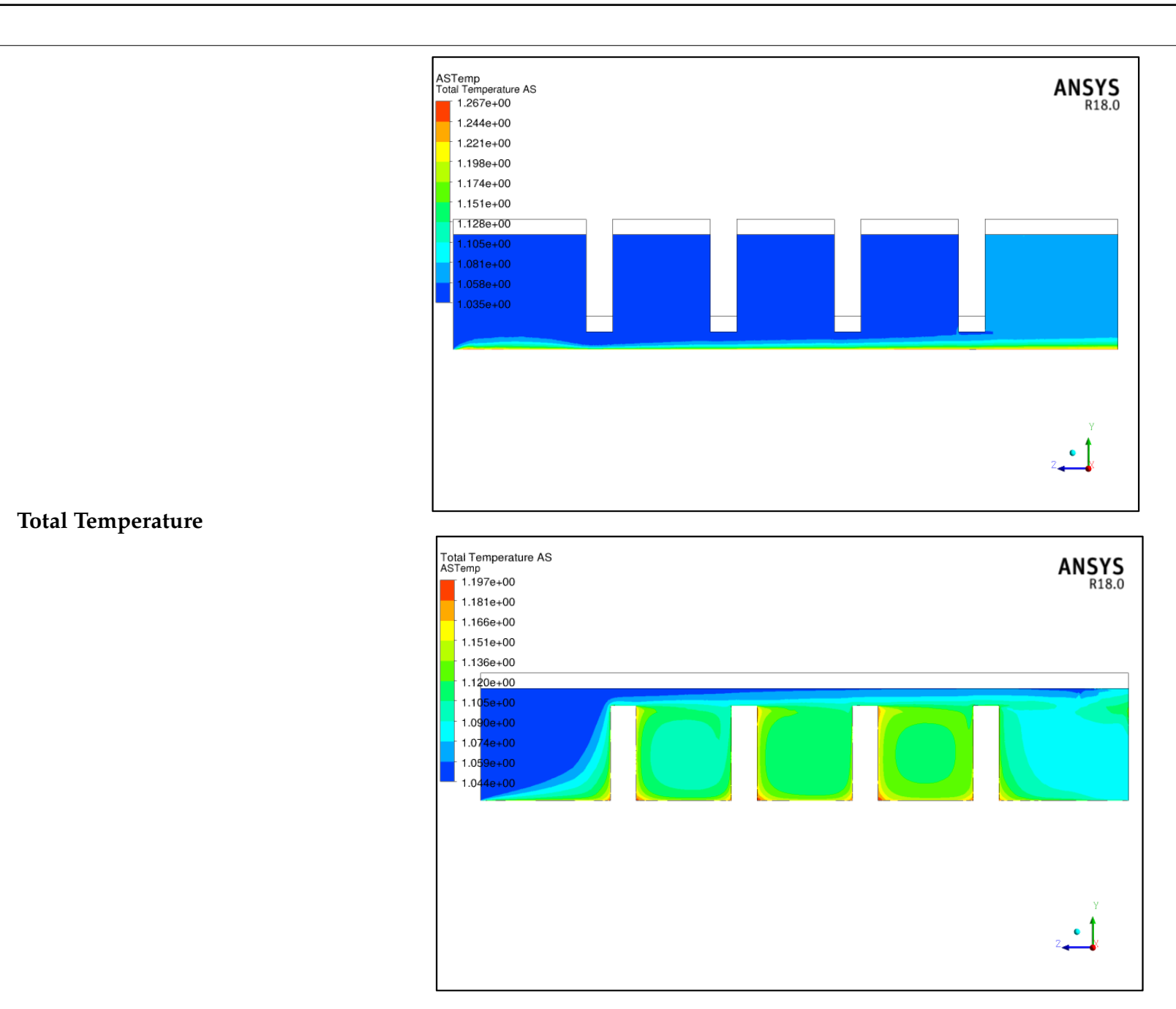

Total Temperature

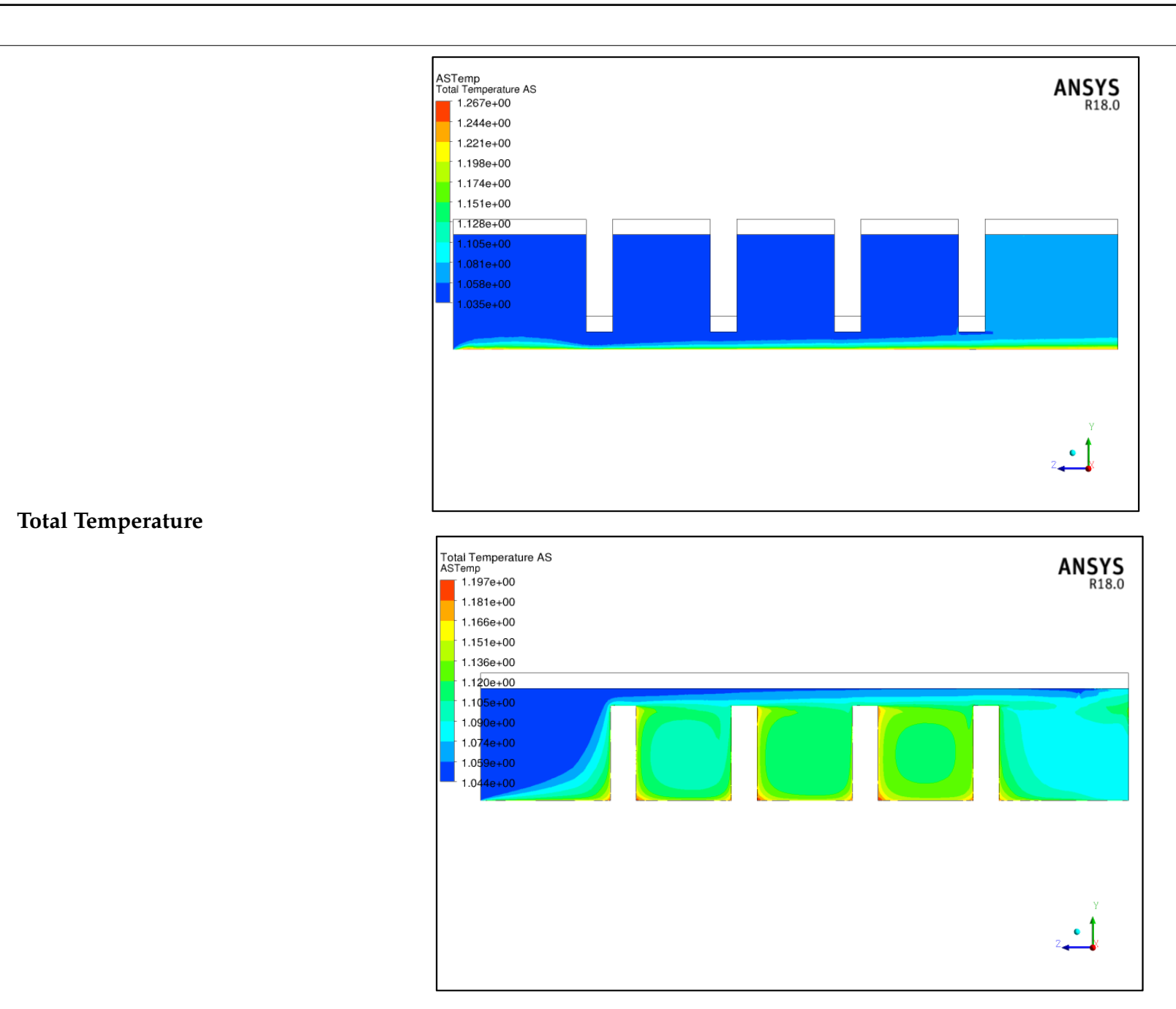

Rotor Teeth 
Table A2. Static pressure fields.

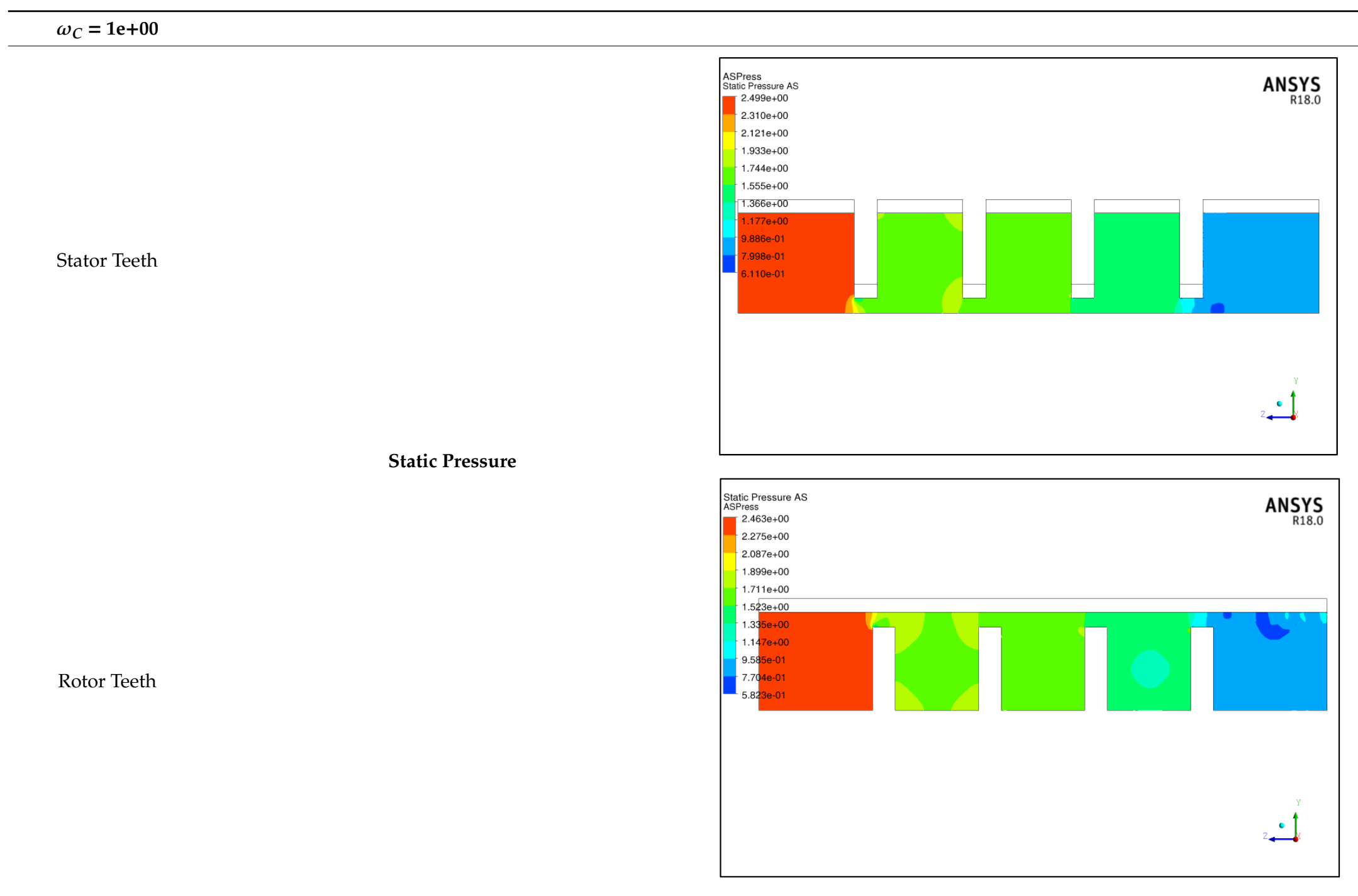


Table A3. Total temperature fields.

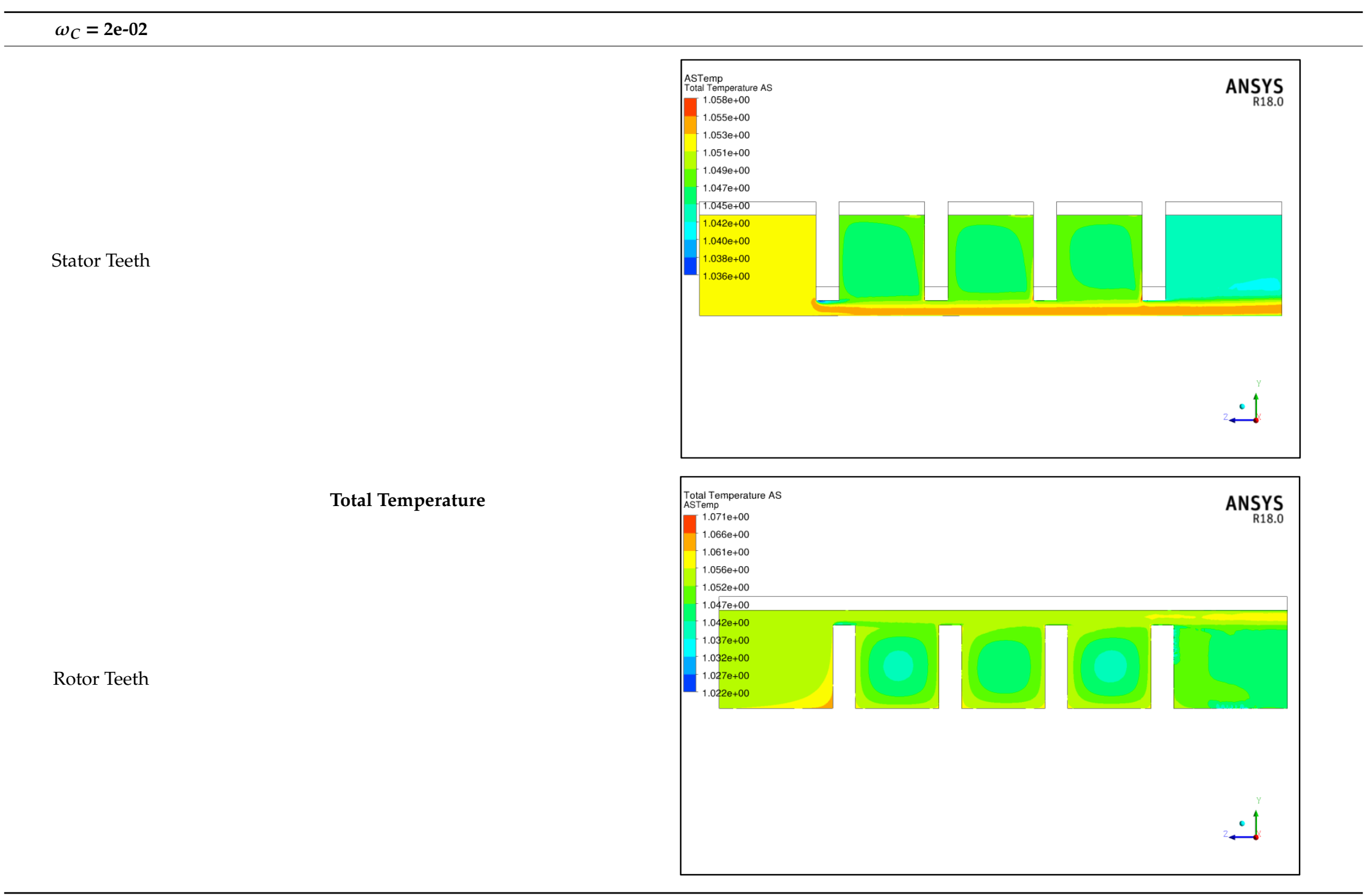


Table A4. Static pressure fields.

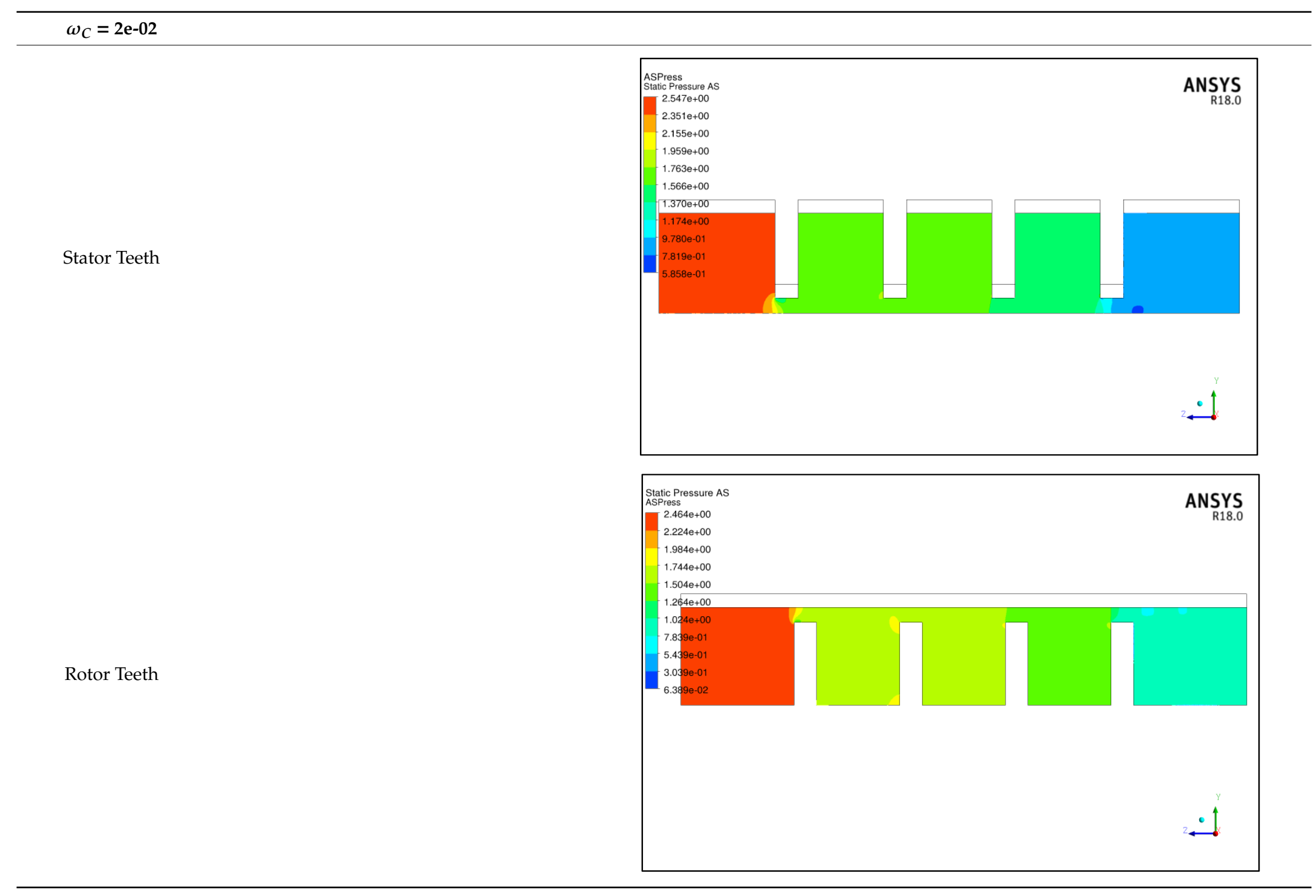


Appendix B. RCCORR = 0.04, Total Temperature and Static Pressure Fields

Table A5. Total temperature fields.

$\omega_{C}=1 \mathrm{e}+00$

Stator Teeth

Rotor Teeth

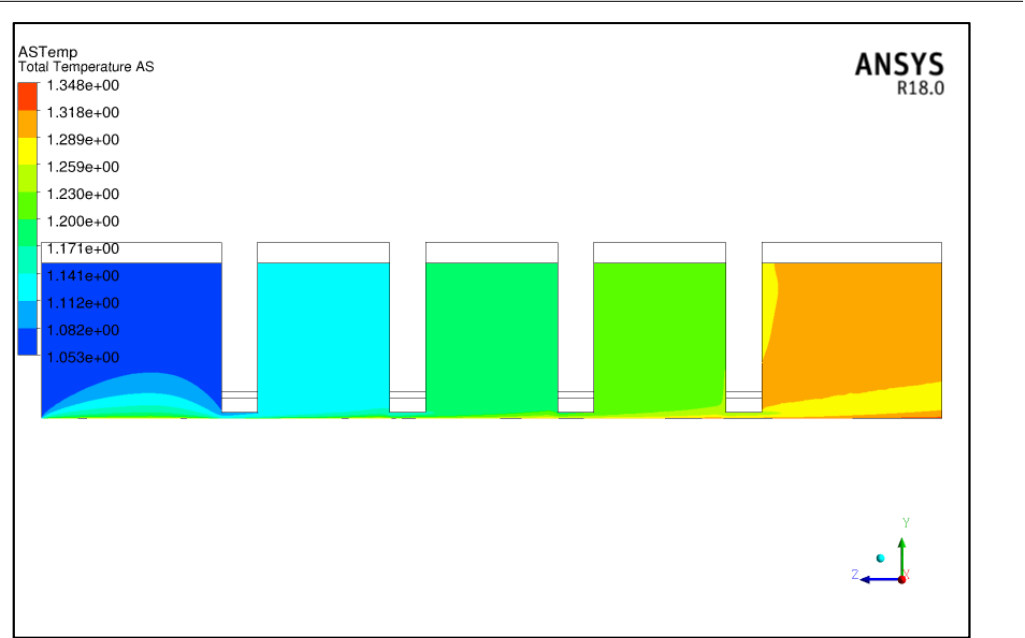

Total Temperature

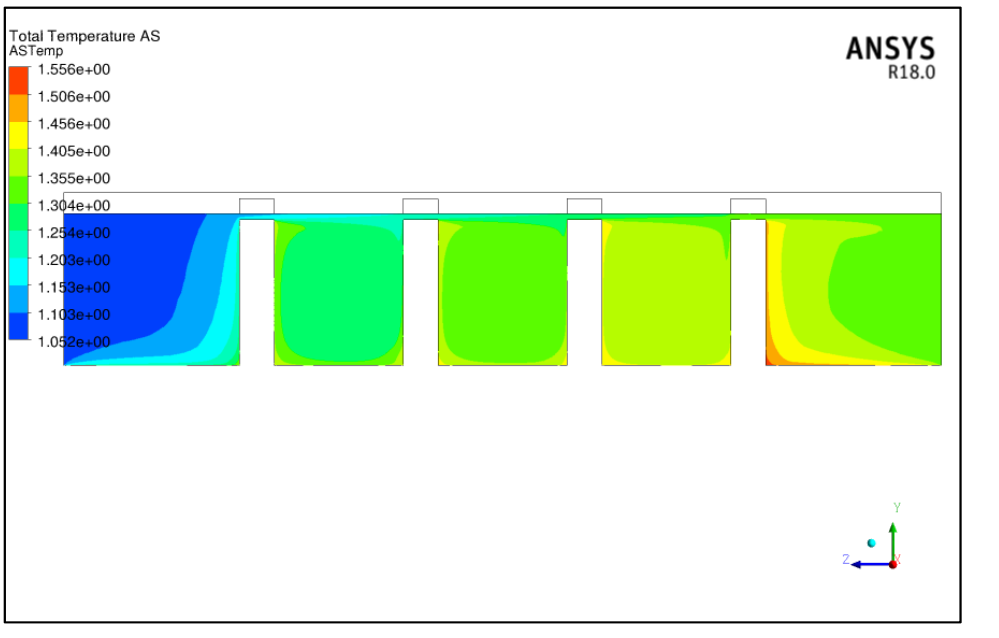


Table A6. Static pressure fields.

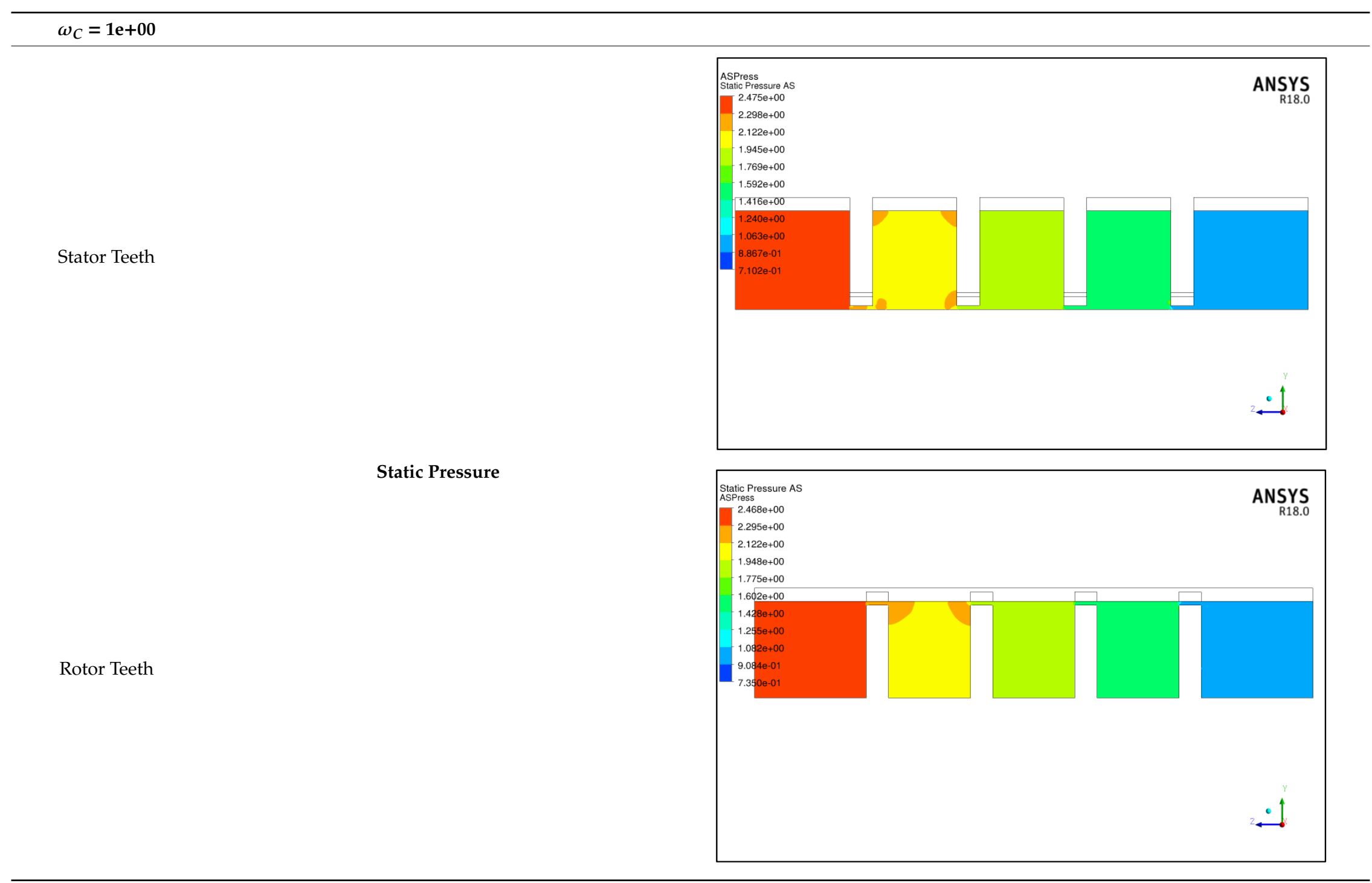


Table A7. Total temperature fields.

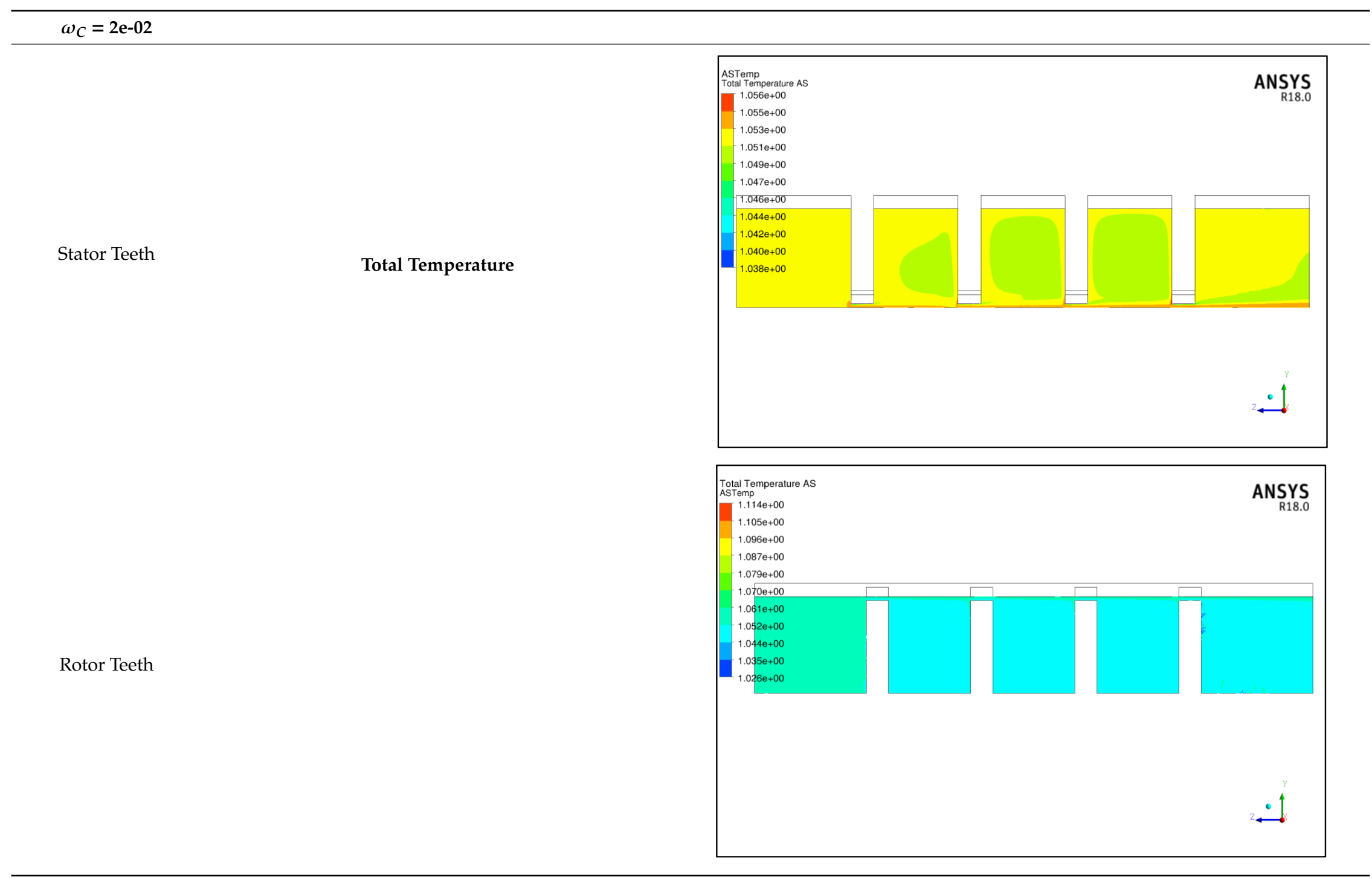


Table A8. Static pressure fields.

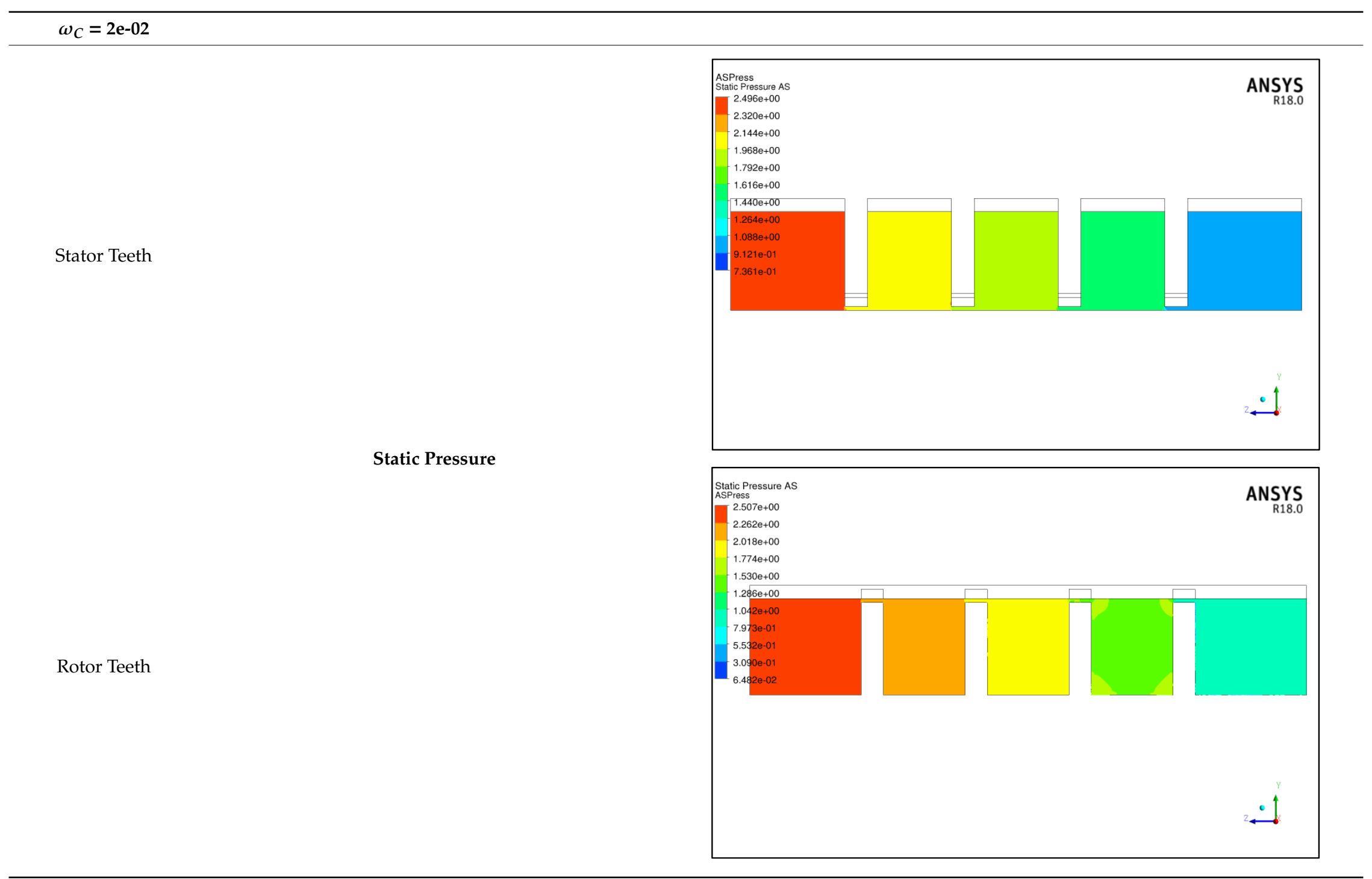




\section{References}

1. Kerrebrock, J.L. The Turbojet. In Aircraft Engines and Gas Turbines; Massachusetts Institute of Technology: Cambridge, MA, USA, 1992; pp. 36-43.

2. Eser, D.; Kazakia, J.Y. Air flow in cavities of labyrinth seals. Int. J. Eng. Sci. 1995, 33, 2309-2326. [CrossRef]

3. Sultanian, B.K. Labyrinth Seals. Internal Flow Systems Modeling; Cambridge University Press: Cambridge, UK, 2018; pp. 237-256.

4. Han, J.-C.; Dutta, S.; Ekkad, S. Numerical Modeling. Gas Turbine, Heat Transfer, and Cooling Technology; CRC Press: Boca Raton, FL, USA, 2013; pp. 771-830.

5. Moustapha, H.; Zelesky, M.F.; Baines, N.C.; Japikse, D. Turbine Durability and Cooling. Axial and Radial Turbines; Concept NREC: White River Junction, VT, USA, 2003; pp. 145-190.

6. Soares, C. Cooling and Load Bearing Systems. In Gas Turbines: A Handbook of Air, Land and Sea Applications; Butterworth Heinemann: Waltham, MA, USA, 2015; pp. 255-278.

7. Meherwan, P. Boyce, Non-contacting Seal. In Gas Turbine Engineering Handbook; Butterworth Heinemann: Waltham, MA, USA, 2012; pp. 579-585.

8. Kurzke, J.; Halliwell, I. Secondary Air System. In Propulsion and Power; Springer Internationally Publishing: Cham, Switzerland, 2018; pp. 687-696.

9. Ilieva, G.; Pirovsky, C. Labyrinth seals with application to turbomachinery. Mater. Sci. Eng. Technol. 2019, 50, 479-491. [CrossRef]

10. Furst, J. Numerical simulation of flows through Labyrinth seals. Appl. Mech. Mater. 2015, 826, 16-22. [CrossRef]

11. Subramanian, S.; Sekhar, A.V.; Prasad, B. Assessment of Analytical Predictions for Radial Growth of Rotating Labyrinth Seals. Int. J. Turbo Jet Engines 2018, 35, 265-279. [CrossRef]

12. Č́žžek, M.; Pátek, Z. On CFD Investigation of Radial Clearance of Labyrinth Seals of a Turbine Engine. Acta Polytech. 2020, 60, 38-48. [CrossRef]

13. Č́žzek, M.; Vampola, T. Labyrinth Seal of Aircraft Turbine Engine Air Flow Calculation at High Viskosity. Acta Mech. Slovaca 2019, 23, 6-12. [CrossRef]

14. Selvaraji, M.; Sam, P.J.; Nirmal, N. Optimization of Labyrinth Seal for Screw Compressor. In Proceedings of the ASME/JSME 2007 Thermal Engineering Summer Heat Transfer Conference, Vancouver, BC, Canada, 8-12 July 2007; pp. 969-975. [CrossRef]

15. ANSYS Help Viewer 18.0. 2016. Available online: https://ansyshelp.ansys.com/account/secured?returnurl= /Views/Secured/corp/v201/en/wb2_help/wb2_help.html\%23wb2_help (accessed on 25 September 2020). 